\title{
Combined spinal-epidural anesthesia using a reduced-dose of spinal bupivacaine and epidural top up leads to faster motor recovery after lower extremity surgeries
}

\author{
Mi Ja Yun, Mi Young Kwon, Do Hun Kim, and Jung Won Lee \\ Department of Anesthesiology and Pain Medicine, National Medical Center, Seoul, Korea
}

Background: The purpose of the present study is to investigate the anesthetic effect of reduced doses of spinal bupivacaine with epidural top ups in comparison with those of spinal bupivacaine and to determine the adequate doses of drugs used during lower extremity surgeries.

Methods: Sixty adult patients were randomized to three different technique groups: S group (10 $\mathrm{mg}$ of spinal bupivacaine), SE1 group (7.5 mg of spinal bupivacaine + epidural 1.5\% lidocaine $10 \mathrm{ml}$ ) or SE2 group (5 $\mathrm{mg}$ of spinal bupivacaine + epidural 1.5\% lidocaine $10 \mathrm{ml}$ ). The level of sensory block, modified Bromage motor scores (MBS), systolic blood pressure and heart rate were recorded for 30 min following anesthesia. Peak sensory block height and MBS, time for sensory regression to L1 and motor recovery to MBS 1 , side effects and operator's satisfaction were noted.

Results: The levels of peak sensory block were similar among the groups $(\mathrm{P}>0.05)$. For the SE2 group, the regression to the $\mathrm{L} 1$ dermatome was faster $(\mathrm{P}=0.004)$ and the maximum MBS was lower $(\mathrm{P}=0.001)$ than that of the other two groups. Motor block recovery to MBS 1 was faster for the SE1 and SE2 groups than for the $\mathrm{S}$ group $(\mathrm{P}<0.001)$. The operator's satisfaction scores of the SE2 group were lower than those of the other two groups $(\mathrm{P}=0.019)$.

Conclusions: During combined spinal-epidural anesthesia, $7.5 \mathrm{mg}$ of spinal bupivacaine and epidural 1.5\% lidocaine 10 $\mathrm{ml}$ produced faster motor recovery than did $10 \mathrm{mg}$ of spinal bupivacaine in patients undergoing lower extremity surgeries. (Korean J Anesthesiol 2014; 66: 28-33)

Key Words: Anesthesia, Epidural, Methods, Motor, Sensory, Spinal.

Received: April 2, 2013. Revised: 1st, June 5, 2013; 2nd, July 16, 2013. Accepted: July 23, 2013.

Corresponding author: Mi Ja Yun, M.D., Ph.D., Department of Anesthesiology and Pain Medicine, National Medical Center, Eulji-ro 245, Junggu, Seoul 100-799, Korea. Tel: 82-2-2260-7370, Fax: 82-2-2262-4766, E-mail: anemjy@gmail.com

(c) This is an open-access article distributed under the terms of the Creative Commons Attribution Non-Commercial License (http:// creativecommons.org/licenses/by-nc/3.0/), which permits unrestricted non-commercial use, distribution, and reproduction in any medium, provided the original work is properly cited. 


\section{Introduction}

Combined spinal-epidural anesthetic technique (CSE) has the advantage of reliability of the subarachnoid block as well as flexibility provided by an epidural catheter [1]. The conventional CSE can be modified to the sequential CSE technique, which is spinal anesthesia with a reduced-dose of local anesthetic and extension of the block with an epidural top-up [2]. Short-acting spinal anesthesia with a reduced-dose of local anesthetic may help patients mobilize earlier and prevent complications associated with delayed motor blockade after the operation such as urinary retention, and patient's discomfort due to immobilization [3].

However, the modified method of CSE has not yet been fully elucidated in patients undergoing lower extremity surgeries. Most of the earlier studies [4-6] were performed using local anesthetics added to opioids in parturients.

We postulate that a spinal block with a reduced-dose of local anesthetic and epidural top up during CSE will provide faster motor recovery of the lower limbs while allowing adequate analgesia for lower extremity surgeries than a spinal block using a conventional-dose of local anesthetic. The primary variable of the current study is the time for regression to modified Bromage motor scores (MBS) 1 and the secondary one is the level of peak sensory block.

The aim of the present study is to investigate the anesthetic effect of spinal block with reduced doses of bupivacaine plus epidural top ups in comparison with that of spinal block using a conventional dose of bupivacaine, and to determine the adequate doses of drugs for lower extremity surgeries.

\section{Materials and Methods}

This study was approved by the Institutional Review Board of our hospital. After obtaining written informed consent, 60 adult patients aged 18 to 90 years (American Society of Anesthesiologists [ASA] physical status classification 1-2) scheduled for elective lower extremity surgeries were randomized to three treatment groups using different methods of combined spinalepidural anesthesia by a computer-generated random table (www.randomizer.org): Group S (control), $10 \mathrm{mg}$ of spinal bupivacaine (Marcaine ${ }^{\circledR}$, Spinal 0.5\% Heavy, $5 \mathrm{mg} / \mathrm{ml}$, AstraZeneca, Sweden); Group SE1, $7.5 \mathrm{mg}$ of spinal bupivacaine + epidural 1.5\% lidocaine $10 \mathrm{ml}(150 \mathrm{mg})$; and Group SE2, $5 \mathrm{mg}$ of spinal bupivacaine + epidural $1.5 \%$ lidocaine $10 \mathrm{ml}$. Patients with deformities of the spinal column, evidence of a coagulapathy, infection at the site of proposed epidural needle puncture, mental disturbance, or neurologic disease were excluded from the study.

Patients were not premedicated. On arrival in the operating room, standard monitoring was applied with electrocardiogra- phy, automated oscillotonometry and pulse oximetry. Baseline systolic arterial pressure (SBP) and heart rate (HR) were recorded every $2 \mathrm{~min}$ until $20 \mathrm{~min}$ and then at $5 \mathrm{~min}$ intervals during the operation. All the patients were prehydrated with $6 \mathrm{ml} / \mathrm{kg}$ of lactated Ringer's solution before induction of the allocated regional anesthetic technique.

Combined spinal-epidural anesthesia was performed with the patient in the lateral decubitus with the leg to be operated on side down. An 18-gauge Tuohy needle was introduced into the L3-4 or L4-5 intervertebral space using a midline or paramedian approach and the epidural space was identified by detecting loss of resistance to air of less than $1 \mathrm{ml}$ of volume. Using the needle through needle technique, an adjustable 29-gauge Whitacre spinal needle (Espocan ${ }^{\circledR}$, B. braun, Melsungen, Germany) was inserted into the subarachnoid space via the Tuohy needle. After the CSF was obtained, $10,7.5$ or $5 \mathrm{mg}$ of bupivacaine was injected over $10 \mathrm{~s}$ without barbotage in the S, SE1 or SE2 group, respectively. Following withdrawal of the spinal needle, a 20-gauge multiorificed catheter was placed $4 \mathrm{~cm}$ cephalad into the epidural space and the Tuohy needle was removed. Patients were then turned into the supine position. For patients in the SE1 and SE2 groups, $10 \mathrm{ml}$ of $1.5 \%$ lidocaine $(150 \mathrm{mg}$ ) was administered through the catheter over $30 \mathrm{~s}$. The completion of this lidocaine injection marked the end of regional anesthesia (taken as time 0 min) for patients in the SE1 or SE2 group.

A research assistant who was unaware of the technique received by each patient, recorded the SBP and HR, the level of sensory block to loss of pain from pinprick induced by a 25-gauge hypodermic needle, and the MBS at 2 or 5 min intervals until $30 \mathrm{~min}$ had passed. The degree of sensory and motor block was measured on the unoperated side of the limbs. The MBS was as follows: $0=$ able to move hip, knee and ankle; $1=$ unable to move hip, able to move knee and ankle; 2 = unable to move hip and knee, able to move ankle; and 3 = unable to move hip, knee and ankle.

Surgery was allowed to start as soon as the sensory block height reached the tenth thoracic dermatome (T10) or $10 \mathrm{~min}$ had elapsed. "Adequate anesthesia" was defined as the achievement of anesthesia at T10 that is associated with pain-free lower extremity surgery. If VAS was more than 30 or the patient wanted analgesics, epidural boluses of $1.5 \%$ lidocaine $10 \mathrm{ml}$ were given as a supplement. If two epidural top ups failed to reduce pain to less than a VAS of 30, general anesthesia was offered to the patient. Intravenous (IV) midazolam 1-2 mg was administered when a patient wanted to be sedated.

The following side effects were noted and recorded: hypotension (defined as SBP $<100 \mathrm{mmHg}$ or a reduction in SBP of more than $20 \%$ from the baseline, which was determined just before the administration of the regional anesthesia), which was treated immediately with $5 \mathrm{mg}$ of IV ephedrine; bradycardia 
(defined as a $\mathrm{HR}<60$ beats/min), which was treated by $0.5 \mathrm{mg}$ of IV atropine; nausea or vomiting (treated with IV ondansetron $4 \mathrm{mg}$ ); and shivering (which was treated by application of an air-warming device or IV meperidine hydrochloride). Two orthopedic surgeons performed all the operations and they graded the operator's satisfaction on a 5 -point scale $(5=$ very good, $4=$ good, 3 = satisfactory, 2 = poor, 1 = very poor).

The sample size was determined from a pilot study of $10 \mathrm{pa}-$ tients in the S and SE2 group each. Twenty patients in each group would confer $80 \%$ power to detect a $35 \%$ difference in the MBS at $30 \mathrm{~min}$ after the anesthesia, accepting an alpha error of 0.016 (0.05 divided by 3 ). Statistical analyses were performed using the statistical software IBM SPSS Statistic 20 with ANOVA (age, weight, height, operation time, $\mathrm{L} 1$ regression time, recovery time to MBS 1), repeated measures ANOVA (change of sensory and motor block, SBP and HR), Pearson's chi-square test (gender, frequency of side effects) or Kruskal-Wallis test (ASA, satisfaction), where appropriate. Posthoc analyses were performed using a Bonferroni correction. Statistical significance was considered when $\mathrm{P}<0.05$.

\section{Results}

Initially, 74 patients were approached, 8 of whom did not consent to participate in the present study. Six out of 74 patients were not eligible. In 3 patients out of the 6 , the operation plan was changed to a more simple one, so the anesthesia was changed to a spinal block. In 1 patient, the body weight was $39 \mathrm{~kg}$ and 2 patients were found to have kyphoscoliosis of their back when they were placed in the lateral decubitus position for the regional anesthesia.

The remaining 60 patients were included and randomized

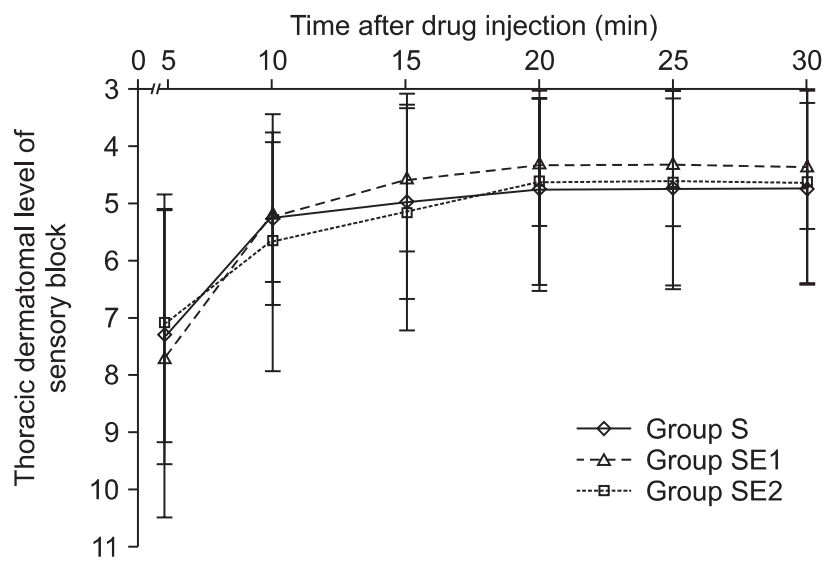

Fig. 1. Changes of sensory block. Data is mean \pm SD. There were no differences in the sensory block throughout the observation period between the three groups $(\mathrm{P}>0.05)$. Group S: spinal hyperbaric $0.5 \%$ bupivacaine $10 \mathrm{mg}$, Group SE1: spinal bupivacaine $7.5 \mathrm{mg}+$ epidural 1.5\% lidocaine $10 \mathrm{ml}$, Group SE2: spinal bupivacaine $5 \mathrm{mg}+$ epidural 1.5\% lidocaine $10 \mathrm{ml}$.

Table 1. Patient Characteristics and Operation Duration

\begin{tabular}{lcccc}
\hline & $\begin{array}{c}\text { Group S } \\
(\mathrm{n}=19)\end{array}$ & $\begin{array}{c}\text { Group SE1 } \\
(\mathrm{n}=19)\end{array}$ & $\begin{array}{c}\text { Group SE2 } \\
(\mathrm{n}=20)\end{array}$ & P value \\
\hline Age $(\mathrm{yr})$ & $66.6 \pm 15.3$ & $65.8 \pm 10.3$ & $59.3 \pm 13.7$ & 0.179 \\
Sex $(\mathrm{M} / \mathrm{F})$ & $6 / 13$ & $7 / 12$ & $9 / 11$ & 0.684 \\
ASA PS (1/2) & $4 / 15$ & $3 / 16$ & $6 / 14$ & 0.472 \\
Weight $(\mathrm{kg})$ & $58.4 \pm 9.1$ & $61.1 \pm 11.4$ & $63.2 \pm 9.5$ & 0.337 \\
Height $(\mathrm{cm})$ & $152.7 \pm 10.7$ & $157.5 \pm 10.1$ & $160.5 \pm 8.4$ & 0.053 \\
Operation duration $(\mathrm{min})$ & $121.6 \pm 38.4$ & $128.4 \pm 50.7$ & $124.5 \pm 80.3$ & 0.938 \\
\hline
\end{tabular}

Values are mean \pm SD or number of patient. Group S: spinal hyperbaric $0.5 \%$ bupivacaine $10 \mathrm{mg}$, Group SE1: spinal bupivacaine $7.5 \mathrm{mg}+$ epidural $1.5 \%$ lidocaine $10 \mathrm{ml}$, Group SE2: spinal bupivacaine $5 \mathrm{mg}$ + epidural 1.5\% lidocaine $10 \mathrm{ml}$. ASA PS: American society of anesthesiologist physical status.

Table 2. Comparison of Sensory and Motor Block

\begin{tabular}{lcccc}
\hline & $\begin{array}{c}\text { Group S } \\
(\mathrm{n}=19)\end{array}$ & $\begin{array}{c}\text { Group SE1 } \\
(\mathrm{n}=19)\end{array}$ & $\begin{array}{c}\text { Group SE2 } \\
(\mathrm{n}=20)\end{array}$ & P value \\
\hline Peak sensory level & $\mathrm{T} 4$ (T8-T3) & $\mathrm{T} 4(\mathrm{~T} 6-\mathrm{T} 3)$ & $\mathrm{T} 4(\mathrm{~T} 8-\mathrm{T} 2)$ & 0.520 \\
Time for peak sensory level (min) & $10.0 \pm 4.7$ & $12.2 \pm 4.6$ & $13.2 \pm 8.0$ & 0.257 \\
Time for sensory regression to L1 (min) & $153.6 \pm 50.2$ & $144.0 \pm 24.1$ & $104.5 \pm 35.6^{*}+$ & 0.004 \\
Maximum motor block (MBS) & $3(1-3)$ & $3(1-3)$ & $2(1-3)^{*+\dagger}$ & 0.001 \\
Time for maximum motor block (MBS) (min) & $5.7 \pm 4.5$ & $9.8 \pm 6.5$ & $8.6 \pm 7.6$ & 0.127 \\
Time for motor recovery to MBS 1 (min) & $246.8 \pm 86.6$ & $125.5 \pm 53.0^{*}$ & $71.6 \pm 42.9^{*}$ & $<0.001$ \\
\hline
\end{tabular}

Values are median (range), mean \pm SD. Group S: spinal hyperbaric $0.5 \%$ bupivacaine $10 \mathrm{mg}$, Group SE1: spinal bupivacaine $7.5 \mathrm{mg}+$ epidural $1.5 \%$ lidocaine $10 \mathrm{ml}$, Group SE2: spinal bupivacaine $5 \mathrm{mg}+$ epidural 1.5\% lidocaine $10 \mathrm{ml}$. MBS: Modified Bromage motor Score $(0=$ able to move hip, knee and ankle; 1 = unable to move hip, able to move knee and ankle; 2 = unable to move hip and knee, able to move ankle; $3=$ unable to move hip, knee and ankle). $* \mathrm{P}<0.05$ compared with Group S. ${ }^{\dagger} \mathrm{P}<0.05$ compared with Group SE1. 
for the study. One patient in the S and SE1 groups each were excluded from the study due to mistakes in data collection. The remaining 58 patients completed the study and their data were statistically analyzed. The demographic data and duration of surgery were comparable in the three groups (Table 1).

The change of sensory block levels including the peak sensory block level and the time to reach it were similar between the three groups $(\mathrm{P}>0.05)$ (Fig. 1, Table 2), but the regression to the L1 dermatome was faster in the SE2 group than in the other two groups $(\mathrm{P}=0.004)$ (Table 2$)$.

The degree of motor block of the SE1 group was lower than that of the control group at 10,15 min following combined spinal-epidural anesthesia $(\mathrm{P}<0.05)$. For the SE2 group, the degree of motor block was lower than that of the control group at each observation time point $(\mathrm{P}<0.05)$ (Fig. 2). Recovery of motor block to MBS 1 was faster in the SE1 and SE2 groups than in the $S$ group $(\mathrm{P}<0.001)$ (Table 2$)$. The operators complained of inadvertent movements of the lower limb during surgery in

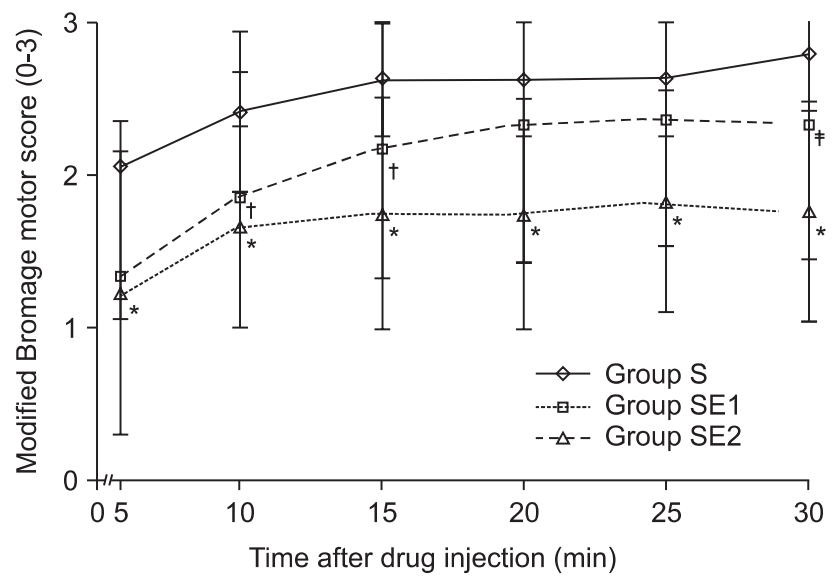

Fig. 2. Changes of motor block. Data is mean \pm SD. The modified Bromage motor scores of the SE1 and/or SE2 groups were lower than that of the $S$ group throughout the observation period $(\mathrm{P}<0.05)$. Group S: spinal hyperbaric $0.5 \%$ bupivacaine $10 \mathrm{mg}$, Group SE1: spinal bupivacaine $7.5 \mathrm{mg}+$ epidural $1.5 \%$ lidocaine $10 \mathrm{ml}$, Group SE2: spinal bupivacaine $5 \mathrm{mg}+$ epidural $1.5 \%$ lidocaine $10 \mathrm{ml} .{ }^{*}{ }^{\dagger} \mathrm{P}<0.05$ compared with Group S. ${ }^{\ddagger} \mathrm{P}<0.05$ compared with Group SE2. four patients of the SE2 group. With regard to the hemodynamic profile, there were no differences between the three groups $(\mathrm{P}>$ 0.05) (Fig. 3, Table 3).

One patient in the SE2 group received general anesthesia because inadvertent movements of one of his legs interfered with the operation. The patient's data was included in the statistical analysis. Epidural supplementation was administered in 4, 5 and 7 patients in the S, SE1 and SE2 groups, respectively $(\mathrm{P}>0.05=$ $0.615)$. One patient in the $S$ group and SE1 group each and 4 patients in the SE2 group received two epidural top ups. One to 2 $\mathrm{mg}$ of IV midazolam was administered in 2, 1 and 1 patients in the S, SE1 and SE2 groups, respectively. Technical difficulty, inadvertent dural puncture or block failure were not encountered in the patients who received CSE. There were no side effects such as nausea, vomiting or shivering. The operator's satisfaction scores were lower in the SE2 group than in the other two groups $(\mathrm{P}=0.019)$ (Table 3).

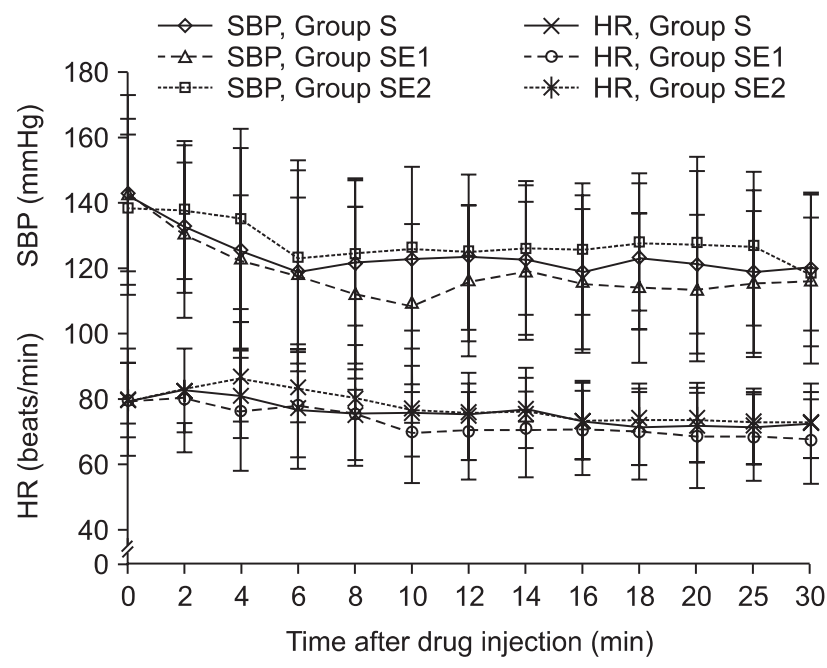

Fig. 3. Changes of systolic arterial pressure (SBP) and heart rate (HR). Data is mean \pm SD. There were no differences in SBP and HR throughout the observation period between the three groups $(\mathrm{P}>0.05)$. Group S: spinal hyperbaric $0.5 \%$ bupivacaine $10 \mathrm{mg}$, Group SE1: spinal bupivacaine $7.5 \mathrm{mg}+$ epidural $1.5 \%$ lidocaine $10 \mathrm{ml}$, Group SE2: spinal bupivacaine $5 \mathrm{mg}+$ epidural $1.5 \%$ lidocaine $10 \mathrm{ml}$.

Table 3. Comparison of Hemodynamic Stability and Operator's Satisfaction

\begin{tabular}{lcccc}
\hline & $\begin{array}{c}\text { Group S } \\
(\mathrm{n}=19)\end{array}$ & $\begin{array}{c}\text { Group SE1 } \\
(\mathrm{n}=19)\end{array}$ & $\begin{array}{c}\text { Group SE2 } \\
(\mathrm{n}=20)\end{array}$ & P value \\
\hline Patients with hypotension & $11(57.9)$ & $14(73.7)$ & $10(52.6)$ & 0.382 \\
Patiens with bradycardia & $6(31.6)$ & $9(47.4)$ & $5(26.3)$ & 0.367 \\
Mean lowest SBP (mmHg) & $105.3 \pm 22.3$ & $100.4 \pm 19.2$ & $107.4 \pm 14.3$ & 0.517 \\
Mean ephedrine requirement (mg) & $4.5 \pm 5.7$ & $5.8 \pm 7.5$ & $3.3 \pm 4.7$ & 0.431 \\
Operator's satisfaction (1-5) & $5(4-5)$ & $5(3-5)$ & $4(2-5)^{*}$, & 0.019 \\
\hline
\end{tabular}

Values are number of patient (\%), mean \pm SD or median (range). Group S: spinal hyperbaric $0.5 \%$ bupivacaine 10 mg, Group SE1: spinal bupivacaine $7.5 \mathrm{mg}+$ epidural 1.5\% lidocaine $10 \mathrm{ml}$, Group SE2: spinal bupivacaine $5 \mathrm{mg}+$ epidural $1.5 \%$ lidocaine $10 \mathrm{ml}$. Operator's satisfaction $(1=$ very poor, $2=$ poor, 3 = satisfactory, 4 = good, 5 = very good). ${ }^{*} \mathrm{P}<0.05$ compared with Group S. ${ }^{\dagger} \mathrm{P}<0.05$ compared with Group SE1. SBP: systolic arterial pressure. 


\section{Discussion}

This study was designed to evaluate the anesthetic effect of spinal block with reduced doses of bupivacaine and epidural top ups with lidocaine in comparison with that of conventional dose of spinal block during CSE and to clarify the adequate doses of drugs for lower extremity surgeries.

There have been some clinical studies that evaluated the beneficial effect of sequential combined spinal epidural block, but most of them were performed in parturients using small doses of spinal local anesthetic plus opioid with an epidural top up of a diluted local anesthetic [4] or normal saline [6]. However, the combinations of local anesthetics in those studies were designed for parturients that underwent cesarean section that lasted less than one hour and to confirm the volume effect of epidural top ups. For clinical practice, there was a need for the authors to define the adequate anesthetic regimen for lower extremity surgeries using two local anesthetics with different durations of action and potencies rather than to just confirm the epidural volume effect during combined spinal epidural block.

In the present study, co-administration of spinal $7.5 \mathrm{mg}$ of bupivacaine and epidural 1.5\% lidocaine $10 \mathrm{ml}(150 \mathrm{mg})$ provided a faster motor recovery profile than with $10 \mathrm{mg}$ of spinal bupivacaine, and anesthesia was extended to provide adequate sensory block for lower extremity surgeries. The significance of the current study that was distinctive from others $[4,6]$ is that sequential administration of two local anesthetics with different durations of action has other advantages than the simple volume effect of an epidural top up during CSE. That is to say, spinal block with a long acting bupivacaine and an epidural top up with a high concentration of intermediate acting lidocaine can provide adequate surgical anesthesia and faster motor recovery than does spinal block only or CSE using saline as an epidural top up.

In the present study, the determination of the lidocaine dose was made according to Trautman et al.s study [7] and was based on the authors' clinical experiences. Trautman et al. [7] reported that epidural lidocaine $(1.5 \%, 10 \mathrm{ml})$ administered after twosegment regression of spinal block (lidocaine, $50 \mathrm{mg}$ ) prolonged the sensory block to pinprick in the thoracolumbar dermatomes by an average of $28 \mathrm{~min}$ and delayed recovery from motor block in the quadriceps, whereas $10 \mathrm{ml}$ of epidural saline was an ineffective top-up and decreased the duration of spinal anesthesia. According to the authors' experiences, the epidural top up using an intermediate duration of lidocaine in high concentration rather than using saline was considered to provide an adequate extension of the sensory and motor block for lower extremity surgery. However, the relatively high concentration of lidocaine as an epidural top up can cause hypotension by sympathetic blockade compared to diluted local anesthetics or saline.
In the current study, $1.5 \%$ lidocaine $(10 \mathrm{ml})$ was used as an epidural top-up and in a relatively higher concentration in comparison with more diluted local anesthetics $(0.25 \%$ levobupivacaine) [4] or the saline [6] used in other studies. It may have caused the incidence of hypotension to be similar to that in the control group. Autonomic denervation in the low thoracic and lumbar regions may result in peripheral sympathetic blockade with vascular dilatation in the pelvis and lower limbs and subsequent hypotension [8]. On the other hand, in Lew et al.s study [6], it was reported that the CSE using epidural volume extension with saline $6.0 \mathrm{ml}$ leads to faster motor recovery but the lowest SBP attained and the total ephedrine dose required were comparable with the control group. So it would be difficult to compare hemodynamic variables between similar studies as they are dependent on many factors including the subjects, dose of local anesthetics, opioids added or other anesthetic techniques used during the CSE.

The anesthetic method used in the SE1 group seems to be adequate for lower extremity surgery of about $120 \mathrm{~min}$ duration as both the time to achieve sensory regression to L1 and modified Bromage motor score of 1 were around $120 \mathrm{~min}$. For the SE1 group, more prolonged motor block was not requested by the surgeons during the operation although recovery from the motor block was faster than that of the control group. The conventional doses of drugs used in spinal anesthesia for lower extremity surgery usually produce a rapid onset of a dense block that lasts beyond the duration of surgery and is associated with delayed ambulation [6]. The faster motor recovery may have an influence on reducing postanesthesia care unit stay [6]. However, the densities and durations of motor and sensory block should be tailored to the kind and duration of operations as incomplete motor block might be contraindicated in some urologic procedures in which inadvertent movements may result in bladder perforation [3].

Several mechanisms have been suggested to explain the extension of spinal blockade when administering an epidural topup during CSE. Leakage of the epidural local anesthetic through the dural hole in the subarachnoid space $[9,10]$ or perineural or transdural spread of epidural local anesthetic bringing "subclinical" analgesia to full analgesic strength $[11,12]$ have been proposed. Local anesthetic administered in the epidural space may enter the subarachnoid space by diffusion through the sleeves of the dura mater that cover the spinal roots as they traverse it [13]. The resting cerebrospinal fluid pressure is typically higher than the pressure in the epidural space, and equilibration is established between the two following dural puncture [14]. Epidural pressure becomes atmospheric by dural puncture and the anesthetic entering the subarachnoid space through the dural hole may act on the volume and circulation of cerebrospinal fluid, resulting in the improved spread of the local anesthetic 
[15]. The compression of the dural sac by the epidurally injected volume of local anesthetic or saline may result in the compression of the cerebrospinal fluid and more extensive spread of the subarachnoid local anesthetic [16]. All these mechanisms may have contributed to the results, such as the similarity in the peak sensory block levels and hemodynamic variables between the three groups in the present study.

There are several limitations in the present study. First, epidural top up of saline was not administered in the control group of patients. This group of patients was not treated with this because this combination is not used commonly in the clinical situation and the volume effect of epidural saline can induce a high thoracic block by the cephalad spread of a conventional dose of spinal bupivacaine. Second, on the next day of surgery, the patients' satisfaction could not be measured as most of the elderly patients did not understand or could not recall the quality of anesthesia including the level of pain experienced during the operation or the discomfort experienced due to immobility after the operation.

In future research, it would be of interest to evaluate these anesthetic techniques with respect to operating room use, postanesthetic care unit discharge times and health care costs.

In conclusion, the co-administration of spinal bupivacaine 7.5 $\mathrm{mg}$ and epidural top up of $1.5 \%$ lidocaine $10 \mathrm{ml}$ provides faster motor recovery than does $10 \mathrm{mg}$ of spinal bupivacaine during CSE in patients undergoing lower extremity surgeries.

\section{References}

1. Rawal N, Schollin J, Wesström G. Epidural versus combined spinal epidural block for cesarean section. Acta Anaesthesiol Scand 1988; 32: 61-6.

2. Rawal N, Holmström B, Crowhurst JA, Van Zundert A. The combined spinal-epidural technique. Anesthesiol Clin North America 2000; 18: 267-95.

3. Kuusniemi KS, Pihlajamäki KK, Pitkänen MT, Helenius HY, Kirvelä OA. The use of bupivacaine and fentanyl for spinal anesthesia for urologic surgery. Anesth Analg 2000; 91: 1452-6.

4. Brizzi A, Greco F, Malvasi A, Valerio A, Martino V. Comparison of sequential combined spinal-epidural anesthesia and spinal anesthesia for cesarean section. Minerva Anestesiol 2005; 71: 701-9.

5. Gunusen I, Karaman S, Sargin A, Firat V. A randomized comparison of different doses of intrathecal levobupivacaine combined with fentanyl for elective cesarean section: prospective, double-blinded study. J Anesth 2011; 25: 205-12.

6. Lew E, Yeo SW, Thomas E. Combined spinal-epidural anesthesia using epidural volume extension leads to faster motor recovery after elective cesarean delivery: a prospective, randomized, double-blind study. Anesth Analg 2004; 98: 810-4.

7. Trautman WJ 3rd, Liu SS, Kopacz DJ. Comparison of lidocaine and saline for epidural top-up during combined spinal-epidural anesthesia in volunteers. Anesth Analg 1997; 84: 574-7.

8. Veering BT, Cousins MJ. Cardiovascular and pulmonary effects of epidural anaesthesia. Anaesth Intensive Care 2000; 28: 620-35.

9. Bernards CM, Kopacz DJ, Michel MZ. Effect of needle puncture on morphine and lidocaine flux through the spinal meninges of the monkey in vitro. Implications for combined spinal-epidural anesthesia. Anesthesiology 1994; 80: 853-8.

10. Swenson JD, Wisniewski M, McJames S, Ashburn MA, Pace NL. The effect of prior dural puncture on cisternal cerebrospinal fluid morphine concentrations in sheep after administration of lumbar epidural morphine. Anesth Analg 1996; 83: 523-5.

11. Carrie LE. Epidural versus combined spinal epidural block for caesarean section. Acta Anaesthesiol Scand 1988; 32: 595-6.

12. Zaric D, Hallgren S, Leissner L, Nydahl PA, Adel SO, Philipson L, et al. Evaluation of epidural sensory block by thermal stimulation, laser stimulation, and recording of somatosensory evoked potentials. Reg Anesth 1996; 21: 124-38.

13. Stienstra R, Dahan A, Alhadi BZ, van Kleef JW, Burm AG. Mechanism of action of an epidural top-up in combined spinal epidural anesthesia. Anesth Analg 1996; 83: 382-6.

14. Telford RJ, Hollway TE. Observations on deliberate dural puncture with a Tuohy needle: pressure measurements. Anaesthesia 1991; 46: 7257.

15. Kumar CM. Combined subarachnoid and epidural block for caesarean section. Can J Anaesth 1987; 34: 329-30.

16. Blumgart CH, Ryall D, Dennison B, Thompson-Hill LM. Mechanism of extension of spinal anaesthesia by extradural injection of local anaesthetic. Br J Anaesth 1992; 69: 457-60. 